\title{
Correction to: Elevated Risk for Obsessive Compulsive Symptoms in Women Pregnant during the COVID-19 Pandemic
}

\author{
Brittain L. Mahaffey ${ }^{1} \cdot$ Amanda Levinson $^{1,2} \cdot$ Heidi Preis $^{2,3} \cdot$ Marci Lobel $^{2}$
}

Published online: 18 August 2021

(c) Springer-Verlag GmbH Austria, part of Springer Nature 2021

\section{Correction to: Archives of Women's Mental Health https://doi.org/10.1007/s11904-021-00568-9}

Blinding was not removed from the Study Design subsection of the Methods section prior to publication. Omitted information is provided below.

Participants were recruited via advertisements on social media (Facebook, Instagram, and Reddit) for the Stony Brook COVID-19 Pregnancy Experiences (COPE) Study- a longitudinal project to assess psychosocial impacts of the COVID-19 pandemic on pregnant women and their children.

The study was approved on April 21, 2020 by the Institutional Review Board of Stony Brook University (IRB2020-00227).

The original article has been corrected.

Publisher's note Springer Nature remains neutral with regard to jurisdictional claims in published maps and institutional affiliations.

The original article can be found online at https://doi.org/10.1007/ s11904-021-00568-9.

Brittain L. Mahaffey

Brittain.Mahaffey@stonybrookmedicine.edu

1 Department of Psychiatry and Behavioral Health,

Renaissance School of Medicine, Stony Brook University,

Putnam Hall, New York, NY 11794, USA

2 Department of Psychology, Stony Brook University, New York, NY 11794, USA

3 Department of Pediatrics, Renaissance School of Medicine, Stony Brook University, New York, NY 11794, USA 